\title{
The causes of the municipal solid waste and the greenhouse gas emissions from the waste sector in the United States
}

\author{
Seungtaek Lee ${ }^{a}$, Jonghoon Kimª and Wai Oswald Chong ${ }^{\mathrm{a}^{*}}$ \\ ${ }^{a}$ School of Sustainable Engineering and the Built Environment, Arizona State University, Tempe, AZ 85287, United States
}

\begin{abstract}
The United State generates the most waste among OECD countries, and there are adverse effects of the waste generation. One of the most serious adverse effects is greenhouse gas, especially $\mathrm{CH} 4$, which causes global warming. However, the amount of waste generation is not decreasing, and the United State recycling rate, which could reduce waste generation, is only $26 \%$, which is lower than other OECD countries. Thus, waste generation and greenhouse gas emission should decrease, and in order for that to happen, identifying the causes should be made a priority. The research objective is to verify whether the Environmental Kuznets Curve relationship is supported for waste generation and GDP across the U.S. Moreover, it also confirmed that total waste generation and recycling waste influences carbon dioxide emissions from the waste sector. The annual-based U.S. data from 1990 to 2012 were used. The data were collected from various data sources, and the Granger causality test was applied for identifying the causal relationships. The results showed that there is no causality between GDP and waste generation, but total waste and recycling generation significantly cause positive and negative greenhouse gas emissions from the waste sector, respectively. This implies that the waste generation will not decrease even if GDP increases. And, if waste generation decreases or recycling rate increases, the greenhouse gas emission will decrease. Based on these results, it is expected that the waste generation and carbon dioxide emission from the waste sector can decrease more efficiently.
\end{abstract}

(C) 2016 The Authors. Published by Elsevier Ltd. This is an open access article under the CC BY-NC-ND license

(http://creativecommons.org/licenses/by-nc-nd/4.0/).

Peer-review under responsibility of the organizing committee of ICSDEC 2016

Keywords: Environmental Kuznets Curve; Granger causality; Greenhouse gas; Municipal solid waste; Recycling; Waste sector

\section{Introduction}

Global Municipal Solid Waste (MSW) generates approximately 1.3 billion tons per year and this is expected to increase to approximately 2.2 billion tons per year by 2025 [1]. The United States generates the most waste per capita among OECD countries [2], approximately 730 kilograms per capita in 2013. Moreover, the United States

\footnotetext{
* Corresponding author. E-mail address: Oswald.Chong@asu.edu
} 
produced the most greenhouse gas emissions among the OECD countries [2]. Approximately $18.1 \%$ of total U.S. methane emissions were generated from the waste landfills sector in 2013, which was the third largest contributor of methane emissions in the United States [3].

Solid waste can result in adverse effects to human health and the environment [4]. In particular, waste produces a large amount of greenhouse gas emissions, which is the most critical issue to global climate change [5]. According to the Intergovernmental Panel on Climate Change (IPCC), the global surface temperature will increase by $4.8^{\circ} \mathrm{C}$, and sea levels will rise by $0.82 \mathrm{~m}$ by 2100 [6]. In addition, the annual global GDP will drop between 5\% and 20\% if greenhouse gas emissions do not decrease immediately. Therefore, the reduction of greenhouse gases is a critical issue to be resolved.

Several efforts have been made in the past to reduce the waste produced by the U.S. government. The U.S. communities' actions, such as technological advancements, environmental regulations, and emphasis on resource conservation and recovery, have significantly reduced the environmental impacts of municipal solid waste, including greenhouse gas emissions [7]. However, neither the solid waste generation nor the recycling rate is decreasing. The U.S. recycling rate is only $26 \%$, which is lower than other OECD countries [8].

The current situation of the U.S. waste sector is severe. Not only is the waste generation per capita significantly high, but so are greenhouse gas emissions from the waste sector. Thus, the main objective of this research is to mitigate the solid waste and greenhouse gases from waste sector. In order to achieve the main objective, first, the causal relationship with solid waste across the United States must be investigated. If the main cause of the solid waste is verified, the amount waste can effectively be decreased. Second, it must be confirmed whether solid waste and recycling waste influences greenhouse gas emissions from the waste sector. By verifying the relationship between the waste and greenhouse gases from the waste sector, an appropriate strategy can be developed for decreasing the amount of greenhouse gases from the waste sector. Lastly, based on the research results, important insights and suggestions can be provided to policymakers on potential ways for reducing the solid waste and greenhouse gas emissions from the waste sector.

\section{Methodology and empirical results}

Two causality models are proposed to achieve the research objectives. The first model is for the Environmental Kuznets Curve (EKC) relationship, which verifies whether the GDP per capita causes MSW generation per capita. The previous research on environmental degradation includes municipal waste per capita, greenhouse gas emissions per capita, dissolved oxygen in rivers, and changes in forested areas relative to GDP per capita, and this relationship is called the EKC [9]. The EKC hypothesis is that there is an inverted- $\mathrm{U}$ relationship between per capita income and environmental degradation [9]. This hypothesis conjectures that initially, environmental degradation tends to get worse as per capita income rises and until per capita income reaches a certain level. At that point, the degradation subsides and drops at the high economic level [9,10]. Thus, economic growth may become a solution rather than a problem [11]. The U.S. annual data from 1990 to 2012 used in this study were collected from various data sources. For the first model, the GDP per capita (in current U.S. dollar) and municipal solid waste generated per capita (in kilograms per capita), which is comprised of various items, such as packaging, furniture, electrical appliances, and food, and does not include industrial, hazardous, or construction waste, were collected from the World Bank website database and OECD website database. The second model confirms how the total MSW and recovery waste, which includes selectively extracted materials from disposed waste for next use as well as recycling and composting waste, causes greenhouse gas emissions from the waste sector. The data for the total MSW and recovery waste generation (in tons) and greenhouse gas emissions from waste sector (in $\mathrm{Tg} \mathrm{CO} 2$ Eq.) were obtained from the U.S. Environmental Protection Agency website database. Figure 1 summarizes the proposed two causality models.

Conventional Granger causality is applied by estimating vector autoregressive (VAR) models, and it requires pretests for the unit root test and the cointegration test. Based on the two pretests, and if cointegration exists, the causality test is applied. However, the unit root and cointegration tests might cause size distortions, which can lead to an inaccurate model for the non-causality test [12]. Moreover, the Johansen-type cointegration test is susceptible to the values of nuisance parameters, so the causality results based upon error correction model (ECM) might be extremely biased [13]. Thus, a modified Wald (MWALD) test in an augmented VAR model is proposed by Dolado and Lütkepohl (1996) and Toda and Yamamoto (1995) [14,15]. The MWALD is simpler and more straightforward 

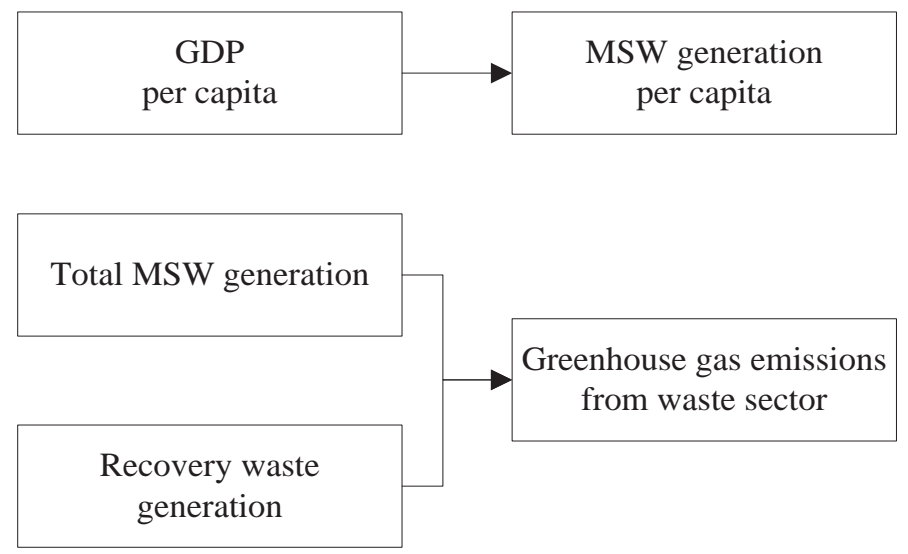

Fig. 1. Proposed causality models.

than other causality tests and does not need pretesting for the cointegration test [16]. The basic idea of the TodaYamamoto (TY) test is artificially to augment the actual lag length (k) of the VAR model by the maximal order of integration (dmax). Once this is done, the VAR model with an order of $(\mathrm{k}+\mathrm{dmax})$ is estimated, and the coefficients of the last dmax lagged vectors are ignored. The asymptotic distribution of the Wald statistic is guaranteed whether the process is stationary or nonstationary, because the TY test requires the estimation of an augmented VAR [17]. In addition, the procedure can avoid the potential pretesting biases that undermine the conventional causality test, since the pretesting for the cointegration test is not required [17,18]. Lastly, since the TY procedure estimates a VAR in level, there is no information loss due to data differencing [19].

Table 1 shows the results of the causal relationship in detail, and it can confirm that only two null hypotheses were rejected at the $5 \%$ of significance level. In the first model, which tried to verify the EKC relationship, there is no causal relationship between GDP per capita and waste generation per capita. This means that even if the GDP per capita increases or decreases, it does not affect waste generation per capita. In addition, there is no reverse causality. In the second model, it was confirmed that total waste generation significantly causes an increase in greenhouse gas emissions from the waste sector, and the sum of the lagged total waste generation coefficients was 0.971866 , which is positive in the VAR model. In addition, it was also proved that recovery waste generation causes greenhouse gas emissions, and the sum of lagged recovery waste generation coefficients was -0.963539 , which is negative in the VAR model. These imply that if the total waste generation increases, greenhouse gas emissions from the waste sector also increase, but if recovery waste increases, greenhouse gas emissions decrease.

Table 1. Results of the Granger causality test.

\begin{tabular}{lllll}
\hline \multicolumn{1}{c}{ Null Hypothesis } & Values & Lag & Probability & Decision \\
\hline First model & & & & \\
\hline GDP per capita $\nrightarrow$ Waste generation per capita & 0.438204 & 3 & 0.9322 & Accepted \\
\hline Waste generation per capita $\nrightarrow$ GDP per capita & 0.595914 & 3 & 0.8974 & Accepted \\
\hline Second model & & & & \\
\hline Total waste generation $\nrightarrow$ GHG from waste & 16.76564 & 3 & 0.0008 & Rejected \\
\hline GHG from waste $\nrightarrow$ Total waste generation & 4.143431 & 3 & 0.2464 & Accepted \\
\hline Recycling generation $\nrightarrow$ GHG from waste & 22.84908 & 3 & 0.0000 & Rejected \\
\hline GHG from waste $\nrightarrow$ Recycling generation & 0.470454 & 3 & 0.9253 & Accepted \\
\hline
\end{tabular}




\section{Discussion}

\subsection{GDP per capita and municipal solid waste generation per capita}

The results showed that the GDP per capita growth does not, by itself, result in environmental improvement (like a decrease in waste generation), and it also means that there is no ECK relationship in waste sector in the United States. This result is in accordance with previous research $[20,21]$. Thus, the government should find an alternative way to solve the waste generation problem. For example, public support and institutional reform are needed to accomplish environmental improvement, and promoting waste recycling also can decrease waste generation, but incentives or compulsion are needed.

Several previous papers have suggested ways to reduce waste. Timlett and Williams (2008) studied increasing recycling rates in households and concluded that personalized incentives and feedback were significantly effective [22]. Wagner and Arnold (2008) introduced a case study of Nova Scotia in Canada [23]. The Nova Scotia government implemented a solid waste management strategy that included restricting disposal, increasing recycling, and increasing the use of diverted materials, and the amount of solid waste production decreased by about $50 \%$ in five years. In addition, Mühle et al. (2010) compared municipal solid waste management in Germany and the United Kingdom [24]. The results showed that the United Kingdom accounts for higher levels of landfill waste. Furthermore, in the United Kingdom the emission of greenhouse gases from waste associated with MSW management is about five times higher than in Germany, where recycling is emphasized. Thus, the U.S. federal and state governments should enact laws that encourage people to reduce the production of solid waste and to improve their recycling habits.

\subsection{Municipal solid waste and recycling waste generation and greenhouse gas emissions from waste}

According to the results, municipal waste generation significantly leads to increased greenhouse gas emissions in the waste sector in the United States. Moreover, the results also verified that the increased generation of recycling waste will decrease greenhouse gas emissions. These results are reasonable, and the results are consistent with previous research. For example, on average, a resident generates approximately $5.9 \mathrm{lb} /$ year of PET beverage containers [25]. If it is possible that all of the PET containers can be recycled, then based on data developed by the EPA and used in Solano et al. (2002) [26], about $10.4 \mathrm{lb} /$ year of greenhouse gases can be avoided [25]. Thus, MSW waste should be reduced and recycling waste should be increased in order to curb greenhouse gas emissions.

Decreasing the waste materials is the most direct way to reduce greenhouse gas emissions from the waste sector, but there can be another way. If the causal relationship between waste and greenhouse gases is broken, greenhouse gases will not increase even if the solid waste increases. For example, the greenhouse gases emitted from the solid waste sector can be used as an energy source because the greenhouse gas is mostly $\mathrm{CH} 4$, which is able to be used for energy. By applying this method, which involves simple technology and can be installed at any site, greenhouse gas emissions can be mitigated [5,27]. Another alternative example is that of increasing recycling rate, and this method is more efficient. According to Morris (1996), recycling conserves more energy than is generated by incineration for most waste materials [28]. Thus, if most of the $\mathrm{CH} 4$ generated from waste is utilized as an energy source or if the recycling rate increases, the greenhouse gas emissions from the waste sector will not increase even if the amount of waste increase, and the causal relationship will be disconnected.

\section{Conclusion}

The United States generates the most waste among the OECD countries, and its recycling rate is lower than that of other OECD countries. Thus, the U.S. government should pay more attention to solve the problem. Municipal solid waste not only contaminates the soil, but also emits greenhouse gases. In order to decrease these adverse effects, the amount of solid waste should be reduced. This study tried to verify the causal relationship between solid waste generation and greenhouse gas emissions from solid waste in the United States. The total amount of solid waste causes greenhouse gas emissions from the waste sector, and recycling waste mitigates these emissions. Thus, 
it is concluded that since there is no causality between GDP per capita and MSW per capita, the government should find alternative strategies to decrease the amount of solid waste per capita.

Based on the research results, several suggestions were made. First, increasing recycling waste is the most critical. Recycling waste not only decreases the amount of solid waste, but also greenhouse gas emissions from the waste sector. In order to increase the recycling waste, the U.S. government should enact a law that can encourage people to recycle waste. According to previous research, personalized incentives and feedback can effectively make people to recycle, so policy makers should develop such incentives. Second, it is recommended that the causal relationship between MSW and greenhouse gas emissions from the waste sector should be broken. One of the methods is to apply the waste to energy technology. In this way, the government should encourage the development of technology that can make efficient use of energy produced by waste. Lastly, the U.S. federal and local governments can make benchmarks for successful waste management using cases like Germany and Nova Scotia as models.

\section{References}

[1] D. Hoornweg, P. Bhada-Tata, What a Waste - A Global Review of Solid Waste Management, Washington, D.C., World Bank, 2012.

[2] OECD, Environment at a Glance 2013: OECD Indicators, OECD Publishing, 2013. http://dx.doi.org/10.1787/9789264185715-en

[3] EPA, Inventory of U.S. Greenhouse gas emissions and sinks: 1990-2012, Fed. Regist. 79 (2014) 10143-10144.

[4] P. Alam, P., K. Ahmade, Impact of solid waste on health and the environment, Int. J. Sustain. Dev. 2 (2013) 165-168.

[5] J. Bogner, R. Pipatti, S. Hashimoto, C. Diaz, K. Mareckova, L. Diaz, P. Kjeldsen, S. Monni, A. Faaij, Q. Gao, T. Zhang, M.A. Ahmed, R.T.M. Sutamihardja, R. Gregory, Mitigation of global greenhouse gas emissions from waste: conclusions and strategies from the Intergovernmental Panel on Climate Change (IPCC) Fourth Assessment Report-Working Group III (Mitigation), Waste Manag. Res. 26 (2008) 11-32. doi:10.1177/0734242X07088433

[6] IPCC, Climate Change 2014: Synthesis Report. Contribution of Working Groups I, II and III to the Fifth Assessment Report of the Intergovernmental Panel on Climate Change [Core Writing Team, R.K. Pachauri and L.A. Meyer (eds.)]. Geneva, Switzerland, IPCC, 2014.

[7] K.A. Weitz, S.A. Thorneloe, S.R. Nishtala, S. Yarkosky, M. Zannes, The Impact of municipal solid waste management on greenhouse gas emissions in the United States, J. Air Waste Manage. Assoc. 52 (2002) 1000-1011. doi:10.1080/10473289.2002.10470843

[8] http://www.oecd.org/

[9] D.I. Stern, M.S. Common, E.B. Barbier, Economic growth and environmental degradation: The Environmental Kuznets Curve and sustainable development, World Dev. 24 (1996) 1151-1160. doi:10.1016/0305-750X(96)00032-0

[10] N. Shafik, Economic development and environmental quality: An econometric, Oxford Econ. Papers, 46 (1994) 757-773.

[11] D.S. Rothman, S.M. De Bruyn, Probing into the environmental Kuznets curve hypothesis, Ecol. Econ. 25 (1998) 143-145.

[12] J.A. Clarke, S. Mirza, A comparison of some common methods for detecting Granger noncausality, J. Stat. Comput. Simul. 76 (2006) 207231. doi:10.1080/10629360500107741

[13] H.Y. Toda, Finite sample performance of likelihood ratio tests for cointegrating ranks in vector autoregressions, Econom. Theory 11 (1995) $1015-1032$.

[14] J.J. Dolado, H. Lütkepohl, Making Wald tests work for cointegrated VAR systems, Econom. Rev. 15 (1996) 369-386. doi:10.1080/07474939608800362

[15] H.Y. Toda, T. Yamamoto, Statistical inference in vector autoregressions with possibly integrated processes, J. Econom. 66 (1995) 225-250. doi:10.1016/0304-4076(94)01616-8

[16] G. Altinay, E. Karagol, Electricity consumption and economic growth: Evidence from Turkey, Energy Econ. 27 (2005) $849-856$. doi:10.1016/j.eneco.2005.07.002

[17] Y. Wolde-Rufael, K. Menyah, Nuclear energy consumption and economic growth in nine developed countries, Energy Econ. 32 (2010) 550556. doi:10.1016/j.eneco.2010.01.004

[18] H.O. Zapata, A.N. Rambaldi, Monte Carlo evidence on cointegration and causation, Oxf. Bull. Econ. Stat. 59 (1997) $285-298$. doi:10.1111/1468-0084.00065

[19] H.G. Doğrul, U. Soytas, Relationship between oil prices, interest rate, and unemployment: Evidence from an emerging market, Energy Econ. 32 (2010) 1523-1528. doi:10.1016/j.eneco.2010.09.005

[20] M.A. Cole, A.J. Rayner, J.M. Bates, The environmental Kuznets curve: An empirical analysis, Environ. Dev. Econ. 2 (1997) $401-416$. doi:10.1017/S1355770X97000211

[21] U. Soytas, R. Sari, B.T. Ewing, Energy consumption, income, and carbon emissions in the United States, Ecol. Econ. 62 (2007) 482-489. doi:10.1016/j.ecolecon.2006.07.009

[22] R.E. Timlett, I.D. Williams, Public participation and recycling performance in England: A comparison of tools for behaviour change, Resour. Conserv. Recycl. 52 (2008) 622-634. doi:10.1016/j.resconrec.2007.08.003 
[23] T. Wagner, P. Arnold, A new model for solid waste management: An analysis of the Nova Scotia MSW strategy, J. Clean. Prod. 16 (2008) 410-421. doi:10.1016/j.jclepro.2006.08.016

[24] S. Mühle, I. Balsam, C.R. Cheeseman, Comparison of carbon emissions associated with municipal solid waste management in Germany and the UK, Resour. Conserv. Recycl. 54 (2010) 793-801. doi:10.1016/j.resconrec.2009.12.009

[25] M. Barlaz, G.C. Cekander, N.C. Vasuki, Integrated solid waste management in the United States, J. Environ. Eng. 129 (2003) $583-584$.

[26] Solano, E., Dumas, R.D., Harrison, K.W., Ranjithan, S.R., Barlaz, M.A., Brill, E.D., 2002. Life-cycle-based solid waste management. II: Illustrative applications, J. Environ. Eng. 128 (2002) 993-1005. doi:10.1061/(ASCE)0733-9372(2002)128:10(993)

[27] M.A. Barlaz, R.B. Green, J.P. Chanton, C.D. Goldsmith, G.R. Hater, Evaluation of a biologically active cover for mitigation of landfill gas emissions, Environ. Sci. Technol. 38 (2004) 4891-4899. doi:10.1021/es049605b

[28] J. Morris, Recycling versus incineration: An energy conservation analysis, J. Hazard. Mater. 47 (1996) 277-293. doi:10.1016/03043894(95)00116-6 